\title{
Em contexto de pandemia: entregadores de aplicativos, precarização do trabalho, esgotamento e mobilização*
}

\author{
In the context of a pandemic: delivery app workers, \\ precarious work, exhaustion and mobilization
}

En el contexto de una pandemia: trabajadores por aplicaciones, precariedad laboral, agotamiento y movilización

\section{Julice Salvagni}

Professora Adjunta no Departamento de Ciências Administrativas da Universidade Federal do Rio Grande do Sul (UFRGS), na área de Estudos Organizacionais. Doutora em Sociologia (UFRGS), Mestre em Ciências Sociais (Unisinos) e Psicóloga (Unisinos). E-mail: julicesalvagni@ gmail.com

\section{Renato Koch Colomby}

Professor do Instituto Federal do Paraná - IFPR. Bacharel, Mestre e Doutor em Administração pela Universidade Federal do Rio Grande do Sul (UFRGS) tendo como área de concentração Gestão de Pessoas e Relações de Trabalho. E-mail: renato.colomby@ gmail.com

\section{Cibele Cheron}

Professora Colaboradora e Bolsista de Pós-doutorado junto ao Programa de Pós-Graduação em Educação da Pontifícia Universidade Católica do Rio Grande do Sul, Brasil. Doutora em Ciência Política pela Universidade Federal do Rio Grande do Sul, Brasil. E-mail: iccibele@gmail.com

\footnotetext{
* Este é um estudo que integra o Fairwork - um projeto de pesquisa-ação coordenado pela Universidade de Oxford em rede com 20 países. No Brasil, o projeto é desenvolvido em conjunto por UNISINOS, UFRGS, UFRJ E USP. A relação completa da equipe do Fairwork Brasil pode ser encontrada aqui: https://digilabour.com.br/projetos/ . Detalhes sobre o projeto Fairwork em https://fair.work
} 


\section{Resumo}

Partindo do entendimento de que o processo de precarização se aprofunda e se intensifica com a chamada uberização, esse ensaio teórico discute as condições de trabalho dos entregadores de aplicativos, categoria que marcou suas reivindicações ante as vulnerabilidades amplificadas no contexto da pandemia de Covid19. Refletindo acerca desses movimentos, a noção de esgotamento é suscitada como ponto central de uma análise sociopsicológica do trabalho que correlaciona a dimensão macrossocial da economia neoliberal a efeitos nefastos da reestruturação produtiva. Assim, infere-se que a noção de esgotamento tem potencial de deslocar os sujeitos a um movimento de devir revolucionário, a qual presumivelmente não seria pensada em uma condição de 'possível', empregando-se a nomenclatura deleuziana.

Palavras-chave: precarização do trabalho; entregadores de aplicativos; esgotamento; Covid-19.

\section{Introdução}

A nova população flutuante, latente e estacionária de homens sem trabalho não é requisito da informática, mas do capital (Coggiola, 1996:86)

A multiplicidade de transformações contemporâneas nas estruturas, relações e formas de organização das sociedades demandam esforços para entender o trabalho extrapolando seus sentidos econômico e técnico, mas também buscando compreender o sujeito que trabalha. $\mathrm{Na}$ esteira do processo de reestruturação produtiva, estreitamente vinculados às novas tecnologias e à informatização, novos arranjos laborais são constituídos, exigindo novas capacidades e implicando na atribuição de outros sentidos ao trabalho. Ao conceber o trabalho como um âmbito relacional cuja relevância estende-se aos aspectos sociais, culturais, simbólicos, econômicos e de garantia da sobrevivência, admite-se sua essencialidade na conformação da subjetividade e do exercício da vida cotidiana, necessariamente produzindo efeitos na saúde física e mental dos trabalhadores (Nardi et al, 2000).

A ascensão do capital rentista, do modelo de acumulação flexível e do neoliberalismo em escala global, aliado ao Estado mínimo, à desestruturação dos direitos sociais e da proteção ao trabalhador, são fatores de precarização da classe trabalhadora. E a recente reafirmação do modelo neoliberal como programa sociopolítico sustenta uma perspectiva assentada na figura do trabalhador empreendedor, subordinado à capacidade de explorar sua própria força de trabalho (Puello-Socarrás, 2014).

Nesse contexto do neoliberalismo servindo aos interesses das relações mercantis transnacionais, enquanto o Estado de bem-estar social vai sendo quebrado, percebe-se uma intensificação da insegurança da classe trabalhadora e o enfraquecimento das instituições que 
deveriam protegê-la. Por sua vez, na uberização há o aprofundamento da exploração e alienação via novas formas de controle que vão além da conexão ou desconexão de um aplicativo por parte dos trabalhadores submetidos ao gerenciamento algorítmico do seu trabalho.

Tendo isso em vista, o presente ensaio teórico discute as condições de trabalho dos entregadores por aplicativos, categoria que marcou suas reivindicações por melhores condições de trabalho, sobretudo, em um contexto de pandemia. Importa citar que as atividades intermediadas pelo digital, já vistas como uma aparente conquista da autonomia dos trabalhadores frente a uma flexibilização do vínculo e da jornada, agora expõem a precarização em um trabalho informal e desprotegido. Todavia, destaca-se que apesar da categoria não consolidar vínculo trabalhista, uma organização grevista dos entregadores foi possível dando novos contornos à mobilização e à união dos trabalhadores nesses novos tempos.

A greve histórica de entregadores brasileiros que trabalham por meio de aplicativos

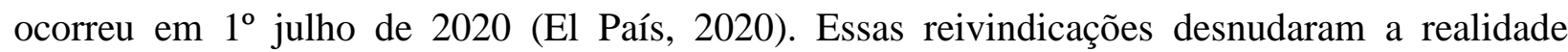
precária que esses trabalhadores estão submetidos. Afinal, o cenário desses entregadores, em tempos de pandemia, tem mostrado algumas preocupações: trabalhadores precarizados sendo dispensados sem qualquer auxílio financeiro e integrantes das plataformas digitais têm trabalhado sem equipamentos de proteção (Harvey, 2020).

A premissa da lógica hegeliana, Safatle (2016) destaca que o processo de esgotamento tem a condição de encerrar formas prévias de relação para que, a partir de então, as relações possam se constituir a partir da contingência de suas situações. Tal destaque permite pensar que, no caso dos entregadores por aplicativo, o esgotamento pode ter sido a forma pela qual a atividade passa a encerrar uma relação que, até então, se constituía com as empresas de trabalho digital. Não sendo visto aqui como uma manifestação tímida, a mobilização dos entregadores por meio da referida greve, pode ter sido efeito do próprio esgotamento, mostrando que há neste conceito um paradoxo, capaz de ilustrar a precarização, por um lado, e a mobilização desse mesmo trabalhador, por outro. Ou seja, ao mesmo tempo em que o esgotamento apresenta a faceta mais cruel do efeito do modelo neoliberal à exploração do trabalho humano, também pode ser visto como um dos mecanismos de reação a essa condição.

A partir da reflexão desses movimentos que a noção de esgotamento pode ser retomada neste artigo como ponto central de uma análise sociopsicológica do trabalho, que correlaciona a dimensão macrossocial da economia neoliberal aos nefastos efeitos da reestruturação produtiva. Tal modelo econômico, que vem aperfeiçoando suas forças de exercer a exploração no trabalho em nome do lucro exponencial, que vem se aperfeiçoando, por meio das plataformas digitais, e adquirindo outros contornos de sutileza às velhas formas de controle do trabalho humano. 
Entende-se que o esgotamento "não é mero cansaço, nem uma renúncia do corpo e da mente, porém, mais radicalmente, é fruto de uma descrença, é operação de desgarramento, consiste em um deslocamento" (Pelbart, 2013:46).

Dessa forma, tem-se como objetivo neste texto de cunho teórico e reflexivo-propositivo: tensionar a noção de esgotamento em uma categoria analítico-política como uma forma de compreender os modos de r(e)existência da categoria de entregadores por aplicativo, partindo do movimento recente de organização coletiva desses trabalhadores no Brasil ocorrido durante a pandemia de Covid-19. Para isso, as próximas seções abarcam: i) entregadores de aplicativo: neoliberalismo, cenário brasileiro e a greve de $1^{\circ}$ de julho; ii) a semântica do esgotamento e as possibilidades de mobilização; e iii) o esgotamento na reestruturação produtiva neoliberal. E nas considerações finais, inclusive, se provoca para que a noção de esgotamento possa ser pensada como forma de mobilização em outras categorias profissionais.

\section{Entregadores de aplicativo: neoliberalismo, cenário brasileiro e a greve de $1^{\circ}$ de julho}

A dimensão do neoliberalismo como aplicação de austeridade político-econômica elitista como pôde ser observada em governos como de Ronald Reagan e Margaret Thatcher, vem ganhando novos contornos no Brasil haja vista os ajustes fiscais propostos e as reformas já efetivadas como a trabalhista e a previdenciária, sem contar com as demais que vem sendo ameaçadas como a reforma administrativa. Em cenários como esses, o mantra de Thatcher que "não há alternativa" mostra-se absoluto: é preciso reduzir o custo do trabalho, disciplinar a mãode-obra, privatizar empresas e o sistema de previdência pública, comprimir os gastos públicos e mecanismos de assistência social. Tudo isso sem nunca questionar os privilégios tributários das elites nem as prioridades do uso do orçamento público, pois o problema é a falta de espírito empreendedor dos pobres ociosos sem responsabilidade individual, que será solucionado pela austeridade que forçará a adaptação dos indivíduos (Dardot; Laval, 2016; Borges, 2018).

E é observando como o neoliberalismo e o próprio capitalismo se reinventam, considerando que as condições de trabalho no Brasil são precarizadas há muito tempo e que há uma piora no cenário após o golpe de 2016, as reformas implantadas, a extinção do Ministério do Trabalho que passou a ser - num ato bastante simbólico - uma secretária do Ministério da Economia e toda a forma de condução da pandemia em nosso país, que esse texto é escrito.

O Brasil, que já vivia o cenário de múltiplas crises incluindo a política e a econômica, teve sua situação agravada com a crise sanitária da pandemia de covid-19, chegando à soma de 13,9 milhões de desempregados, levando em consideração os números do $4^{\circ}$ trimestre de 2020 
(IBGE, 2021). É na confluência entre desemprego, desalento com o mercado formal e o surgimento de novos formatos de trabalho que milhares de trabalhadores buscam alternativas de sobrevivência. Nesse sentido, a conjuntura é fértil para a ocorrência de esgotamento, especialmente quando esse "exige um certo esgotamento fisiológico" (Deleuze, 2010:69), tão presente nos trabalhadores submetidos a jornadas extenuantes.

É nesse contexto que os fenômenos da economia compartilhada e da gig economy ganharam visibilidade por meio de aplicativos de transporte privado de passageiros, que passaram a operar no ano de 2014 a partir do ingresso da norte-americana Uber. O entregador por aplicativo, assim como os demais trabalhos intermediados pelo digital, em um primeiro momento foi tratado como uma aparente conquista da autonomia dos motoristas frente a uma flexibilização do vínculo e da jornada de trabalho. Tal fenômeno, também abordado em teoria pelos conceitos de empreendedor de si mesmo (Barbosa, 2011; Abílio, 2019), pode ser identificada na imposição da pejotização ou da informalidade presente no modus operandi dos aplicativos de mobilidade, por exemplo. Logo, para quem busca uma atividade remunerada, as plataformas digitais, apesar de inserção dos trabalhadores produtivamente, ampliaram a insegurança e a desproteção (Moretto; Macambira, 2020).

O fortalecimento de regras que precarizam as relações laborais só são possíveis, em grande parte, pela característica monopolista das empresas que prestam serviços de entrega por aplicativo. O mercado, no Brasil, centrado na entrega de refeições, é controlado por quatro grandes empresas: iFood, Rappi, Uber Eats e Loggi. Em 2019, o setor faturou R\$ 15 bilhões, o que representou um crescimento de cerca de $20 \%$ em relação a 2018, segundo levantamento da Associação Brasileira de Bares e Restaurantes (ABRASEL, 2020a). A entidade projetava que o faturamento do setor, em 2020, chegaria a R\$ 18 bilhões, mas, com o fechamento dos salões de bares e restaurantes e a adesão em massa ao sistema de delivery, acredita-se que esse valor possa ter sido ainda maior.

Além do grande impulso ao setor, que pode ser explicado pelo surgimento de novas plataformas e pela capilaridade do sistema, o distanciamento social potencializou a utilização desses serviços (ABRASEL, 2020a; 2020b). A partir da Pesquisa Nacional por Amostra de Domicílios referente aos impactos da Covid-19 (PNAD Covid), estima-se que o número de ciclistas e motociclistas, entregadores de aplicativos, passou dos cerca de 250 mil, em 2019, para mais de 645 mil no primeiro semestre de 2020. Esse quantitativo representa em torno de $15 \%$ do total de trabalhadores brasileiros na informalidade, um contingente que ainda inclui os motoristas de aplicativos de transportes e uma série de atividades não digitais, como as dos vendedores ambulantes e outros prestadores de serviços (BBC News Brasil, 2020). 
Trabalhadores informais são aqueles que

[...] não são cobertos pela legislação trabalhista e, portanto, não estão sujeitos às regras
formais trabalhistas ou à correspondente justiça do trabalho, tendo acesso apenas à
justiça comum e aos tribunais de pequenas causas. Além disso, não contribuem para a
seguridade social e, portanto, não usufruem de sistemas de proteção proporcionados
pelo Estado de Bem-Estar Social. A maioria desses trabalhadores está ocupada em
atividades de baixa produtividade e, consequentemente, sua renda é inferior. Por fim,
muitos dos que atuam na informalidade vivem na pobreza ou pobreza extrema e
integram o que os analistas de políticas públicas denominam de grupos vulneráveis
(GEPOLT, 2020:320).

Corroborando tal descrição, os entregadores relatam que, na contramão do desempenho econômico das empresas de delivery, suas condições de trabalho têm piorado, especialmente no contexto da pandemia. Em pesquisa de abril de 2020, em 29 cidades brasileiras, Abílio et al. (2020) identificaram queda na remuneração dos trabalhadores, aumento das jornadas de trabalho e exposição aos riscos de contaminação por SARS-COV-2, sem o fornecimento de equipamentos de proteção pelas plataformas. Ou seja, é possível considerar que informalidade, a pobreza e a exposição ao risco são condições associadas. Sem atingir a totalidade da população, o trabalho informal, cuja desproteção é intencionalmente legitimada pelo Estado, passa a assolar especialmente o chamado exército industrial de reserva, termo cunhado por Karl Marx no século XIX, que faz referência ao excluídos pelo capital produtivo: “[...] a acumulação capitalista sempre produz, e na proporção de sua energia e de sua extensão, uma população trabalhadora supérflua relativamente, isto é, que ultrapassa as necessidades médias da expansão do capital, tornando-se, desse modo, excedente" (Marx, 1989:731).

Ao que se refere aos sujeitos dessa pesquisa, os dados permitem esboçar um perfil dos entregadores: homens (94,6\%), autodeclarados pardos (44\%) ou brancos (39,9\%), entre 25 e 44 anos $(78,2 \%)$. Dentre eles, $70,5 \%$ trabalham em duas ou mais plataformas. Antes da pandemia, $57 \%$ trabalhavam mais do que nove horas por dia, percentual que subiu, durante a pandemia, para $62 \%$. Também durante a pandemia, 51,9\% relataram trabalhar durante os sete dias da semana, e 58,9\% tiveram queda nas suas remunerações: os que declararam obter renda semanal de até R \$260,00 passaram de 17,8\% para 34,4\%. Segundo a pesquisa, 57,7\% dos entregadores afirmaram não ter recebido qualquer auxílio das plataformas para evitar contraírem Covid-19. Assim, compreende-se que a categoria está enfrentando uma destacada desvalorização da força de trabalho "daqueles que já se encontravam nesta atividade antes da pandemia, prática que seria amparada pelo aumento do contingente de trabalhadores de reserva e adoção de forma nociva de uma política de aumento do número de entregadores" (Abílio et al., 2020:9).

Mesmo que se entenda que se trata de uma categoria multifacetada, que apresenta uma heterogeneidade em sua composição enquanto grupo, esses dados coadunam a manifestações de 
algumas lideranças que vem buscando representar esses trabalhadores, como Paulo Lima, de 31 anos, entregador em São Paulo, que afirmou, em entrevista:

Quando esses aplicativos chegaram aqui, venderam uma mentira para nós. A mentira era de que somos empreendedores, e nós acreditamos. As empresas não querem lidar com direitos: rescisão, férias, $13^{\circ}$ salário... Hoje, os entregadores estão começando a se ver como trabalhadores, e que precisam se manifestar para conseguir seus direitos (Machado, 2020, on-line).

Nesse cenário, em $1^{\circ}$ julho de 2020, em meio à pandemia de Covid-19, os trabalhadores brasileiros que fazem entregas via plataformas digitais, paralisaram seus serviços. O movimento envolveu entregadores por aplicativos como Rappi, iFood, Uber Eats, Loggi, Glovo e James em pelo menos 13 estados e no Distrito Federal. Cidades como São Paulo, Belo Horizonte, Brasília, Fortaleza e Salvador registraram grandes manifestações de rua denunciando a exploração desmedida da categoria com a paralisação de carros, motos e bicicletas (De Carvalho et al., 2020).

A greve responde à precarização extrema do labor dos entregadores de aplicativos, que, de forma inédita, reivindicam aumento do valor mínimo recebido por entrega, fim dos desligamentos ou "bloqueios" unilaterais, indevidos ou sem prévio aviso (quando a plataforma deixa de repassar entregas ao trabalhador), cobertura securitária para roubos, acidentes e perda da vida, além do recebimento de uma verba de auxílio para custear a aquisição de equipamentos de proteção e eventuais atendimentos médicos ou hospitalares (Consiglio, 2020).
Percebido como o movimento trabalhista mais importante desde o início do ciclo grevista iniciado com as greves dos trabalhadores das hidroelétricas de Santo Antônio e Jirau, em Rondônia e Belo Monte no Pará, realizadas em 2011 e 2012, até a greve geral de 28 de abril de 2017 com mais de 40 milhões de trabalhadores paralisados, as mobilizações dos chamados trabalhadores das plataformas digitais têm colocado, novamente, o instrumento político da greve no centro das estratégias de luta por direitos no país (De Carvalho et al., 2020:3).

A "greve" ganhou apoio nas redes sociais, com o compartilhamento das reivindicações da categoria, indicado pela hashtag "\#brequedosapps" que trazia consigo o apelo para que os consumidores não realizassem pedidos. Esse encontro, portanto, que é a integração organizada dos trabalhadores, pode ser resultado de um movimento criado a partir da eliminação de possibilidades dado pelo esgotamento que, metaforicamente, pode ser considerado como um profundo suspiro que culmina em um "grito" que acorda a si e aos demais dizendo "basta"! Basta no sentido de enxergar "aquele que é empreendedor de si mesmo, num escravo de si mesmo" (Han, 2017:106) em uma linguagem característica da Sociedade do Desempenho. Aproveita-se para resgatar aqui, mesmo que não seja o foco do artigo, que diferentes autores já buscaram compreender os diversos momentos sociohistóricos e se esforçaram em denominá-los, 
a exemplo da Sociedade Disciplinar (Foucault, 2005), da Sociedade de Controle (Deleuze, 1990), da Sociedade do Desempenho, da Sociedade do Cansaço e da Sociedade do Esgotamento (Han, 2017).

\title{
A semântica do esgotamento e as possibilidades de mobilização
}

Habermas é enfático ao decretar o esgotamento das energias utópicas. Neste sentido, há um alargamento do conceito de esgotamento que, para o autor, passa a definir a situação da sociedade global contemporânea. Organizada em uma lógica de dominação irremediável, resta vislumbrar o futuro com um pessimismo que é parte do sintoma do esgotamento.

\begin{abstract}
O horizonte do futuro estreitou-se e o espírito da época, como a política, transformou-se profundamente. $\mathrm{O}$ futuro afigura-se negativamente; no limiar do século XXI desenha-se o panorama aterrador da ameaça mundial aos interesses da vida em geral: a espiral armamentista, a difusão incontrolada de armas nucleares, o empobrecimento estrutural dos países em desenvolvimento, o desemprego e os desequilíbrios sociais crescentes nos países desenvolvidos, problemas com o meio ambiente sobrecarregado, altas tecnologias operadas às raias da catástrofe, dão as palavras-chave que invadiram a consciência pública através dos meios de comunicação de massa. As respostas dos intelectuais refletem uma perplexidade não menor do que a dos políticos. Não é de forma alguma apenas realismo se uma perplexidade aceita temerariamente coloca-se cada vez mais no lugar de buscas de orientação que apontem para o futuro. A situação pode estar objetivamente ininteligível. Contudo, essa imperspicuidade é também uma função da presteza de ação de que uma sociedade se julga capaz. Trata-se da confiança da cultura ocidental em si mesma (Habermas, 1987:104).
\end{abstract}

Partindo dessas reflexões sobre a modernidade, tensiona-se o esgotamento das energias utópicas como uma espécie de desequilíbrio civilizacional que pode vir a evidenciar múltiplos e contraditórios elementos, implícitos ou explícitos. Se por um lado, o autor nos auxilia a visualizar - na livre comunicação dos indivíduos - uma capacidade de união de interesses universais e a promoção da emancipação humana; em contraste, ao observar os movimentos que transformam a autonomia em dependência e a emancipação em opressão, o autor destaca que certas inovações sociais são marcadas por ambiguidades. Sendo assim,

[...] a energia nuclear, a tecnologia de armamentos e o avanço no espaço, a pesquisa genética e a intervenção da biotecnologia no comportamento humano, a elaboração de informações, o processamento de dados e os novos meios de comunicação são técnicas de consequências intrinsecamente ambivalentes. E quanto mais complexos se tornam os sistemas necessitados de controle, tanto maiores as probabilidades de efeitos colaterais disfuncionais. Nós percebemos diariamente que as forças produtivas transformam-se em forças destrutivas e que a capacidade de planejamento transforma-se em potencial desagregador (Habermas, 1987:105).

Habermas (1987:105) destaca ainda que "alastra-se a suspeita de que o esgotamento das energias utópicas denuncia não apenas um dos estados de ânimo passageiros do pessimismo cultural, mas toca mais fundo". Ou seja, "ele poderia denunciar uma transformação da moderna 
consciência do tempo em geral". Descrevendo o esgotamento do Estado de bem-estar social, o autor reforça que:

É justamente a falta de alternativas, talvez mesmo a irreversibilidade dessas estruturas de compromisso (pelas quais se continua a lutar), que nos põe diante do seguinte dilema: o capitalismo desenvolvido nem pode viver sem o Estado social nem coexistir com sua expansão contínua. As reações mais ou menos desorientadas a este dilema indicam que o potencial de sugestão política da utopia de uma sociedade do trabalho está esgotado (Habermas, 1987:109).

Para Pelbart (2013:39), o esgotamento é um termo que revela "de maneira aguda, embora enigmática, a passagem hesitante e não necessária entre catástrofe e criação, bem como a reversibilidade entre o 'Nada é possível' e o 'Tudo é possível”'. Mais uma vez, a conotação de uma possibilidade ao agir coletivo, de reação ao modelo neoliberal em suas diferentes formas de exploração pelo trabalho.

Apesar de o personagem descrito por Deleuze e apropriado por Pelbart ser uma figura passiva em um primeiro momento, anulado pela reprodução exaustiva de uma ação sem sentido, ele vai ganhando expressividade e movimento a medida em que vai sendo construído. Tal instância política do agir é contemplada, inclusive, pela noção de agenciamento. Assim, como em um movimento de recapturar a exterioridade, o agenciamento "tende a conter seu fora, e essa exterioridade 'irredutível' renasce incessantemente e faz parte do próprio sistema" (Pelbart, 2013:42). Com isso, para o mesmo autor, o possível deixa de ficar confinado no domínio da imaginação e se torna coextensivo à realidade na sua produtividade própria. Criada a brecha para movimento de insurreição ou de revolução, inverte-se a relação entre o acontecimento e o possível. Tais momentos, "sejam individuais ou coletivos (como Maio de 68), correspondem a uma mutação subjetiva e coletiva em que aquilo que antes era cotidiano se torna intolerável, e o inimaginável se torna pensável, desejável, visível" (Pelbart, 2013:45).

É indispensável ao debate, fazer uma distinção conceitual entre o esgotamento e o cansaço. Deleuze (2010:67), destaca que o esgotamento é muito mais do que o cansaço. O cansado "não dispõe mais de qualquer possibilidade (subjetiva) - não pode, portanto, realizar a mínima possibilidade (objetiva)". Tal extrato dá a noção de que o cansaço é algo inerente ao exercício da força de trabalho. Assim, ao ser passível de descanso, não é exatamente uma possibilidade, no sentido criativo da mobilização racional. Por outro lado, o "esgotado esgota todo o possível", fazendo com que não surja outra possibilidade no círculo de variações que opera por meio da exclusão.

Bem diferente do cansaço, portanto, está o esgotamento. Este último "combina-se o conjunto das variáveis de uma situação, com a condição de renunciar a qualquer ordem de preferência e a qualquer objetivo, a qualquer significação. Não é mais para sair nem para ficar, e 
não se utilizam mais dias e noites" (Deleuze, 2010:69). Tal referência pode ser alusiva à realidade de trabalho dos entregadores por aplicativo. A falta de contorno ao trabalho nessa mediação das plataformas, somada ao fato de a baixa remuneração levar a exaustivas jornadas de trabalho, ou mesmo a sobreposição de distintas atividades remuneradas, permite pensar em essa renúncia referida por Deleuze.

Neste sentido, o caráter paradoxal do conceito permite assumir a perda de sentido da ação, ao pensar que

[...] apenas o esgotado pode esgotar o possível, pois renunciou a toda necessidade, preferência, finalidade ou significação. Apenas o esgotado é bastante desinteressado, bastante escrupuloso. Ele é forçado a substituir os projetos por tabelas e programas sem sentido. O que conta para ele é em que ordem fazer o que deve e segundo quais combinações fazer duas coisas ao mesmo tempo, quando ainda necessário, só por fazer. (Deleuze, 2010:69).

Por outro lado, há no esgotamento as possibilidades do devir, já que nessa experiencia rizomática, a força colocada em questão gera um movimento, um turbilhão, com possibilidade de criação de devir revolucionário. Neste sentido, quando acontece o esgotamento, surge uma potencialidade. A potencialidade "é um duplo possível. É a possibilidade de que um acontecimento, ele próprio possível, se realize no espaço considerado. A possibilidade de que alguma coisa se realize, e de que algum lugar o realize" (Deleuze, 2010:69). Há, portanto, quatro funções do esgotamento que Deleuze reconhece a partir da análise de Beckett: "primeiro lugar, o esgotado cria séries exaustivas das coisas; em segundo lugar, ele estanca os fluxos de vozes; em terceiro lugar, ele dissipa a potência da imagem e, finalmente, o esgotado extenua as potencialidades do espaço" (De Vivvar, 2017:6).

A propósito, entende-se que a aproximação do conceito de esgotamento pode ser feita à recente condição do movimento sindical de uma série de categorias de trabalho no Brasil. Conforme relatado em estudo que reinterpreta a ocorrência de greves no país: "os aspectos organizacionais ou institucionais, internos ao movimento sindical, explorados nesta análise indicam que a forte fragmentação e descentralização na base da estrutura sindical e a concorrência na cúpula têm clara relação com o número de greves” (Ferraz, 2018:196).

Seja por pressões do neocorporativismo, seja pelo fogo cerrado de forças políticas, seja por questões de disputa interna: há uma tendência de se debilitar a perspectiva de classe que caracterizou a luta sindical no Brasil (Alves, 2000; Cardoso, 2015). Especialmente no trabalho mediado por aplicativos digitais, a informalidade acaba sendo em elemento que, dentre outras tantas coisas, prejudica propositalmente a formalização das mobilizações via sindicatos estabelecidos. Sendo que o trabalhador não é formalmente vinculado a uma organização, a luta sindical tende a se enfraquecer. Contudo, e paradoxalmente a esse aspecto, o que se vê no caso 
dos entregadores de aplicativos foi uma organização informal que ganhando corpo, passando ser reconhecida por meio da criação de associações.

Em se tratando especificamente dos entregadores por aplicativo, De Carvalho et al. (2020:23) consideram que

[...] avaliando o futuro do movimento, talvez o desafio resida no plano da articulação e interlocução entre o sindicalismo já constituído e as novas formas de mobilização, uma vez que existem associações e sindicatos que representam parte da categoria. Outro desafio que se impõe é a busca pela incorporação de novos trabalhadores nos processos de luta, além de potencializar o apoio de outros setores profissionais e dos próprios consumidores desses serviços.

Ou seja, o legado dos movimentos sindicais no Brasil indica ter tido um papel decisivo a essa outra forma de mobilização, não me menos legítima, mas que ainda precise se constituir em um outro espaço. É indicado que tal forma de mobilização que incorpore as mudanças recentes na forma de trabalhar, contemplando as nuances provocadas pelo advento da tecnologia e pela precarização contina da perda do vínculo de trabalho. Mas, além disso, cabe uma preocupação estratégica em relação aos conchaves corporativos, midiáticos ou políticos que seguem buscando invalidar, reprimir e marginalizar a luta operária.

Em outro aspecto, o conceito de esgotamento e a própria adesão inicial aos trabalhos por aplicativos perpassam a figura do manager. Para Safatle (2016:222), "esse é um exemplo do esgotamento da ética do trabalho derivada do protestantismo e do advento de um modelo de ética do trabalho derivada da produção estética". Tal compreensão leva inferir que esse esgotamento do manager é o que pode ter contribuído para a ascensão dos aplicativos no sentido de eles darem a falsa compreensão de que ali não há uma voz de comando, apenas por esse controle não ser personificado. Ou seja, não é porque não se um chefe que ele não exista, como refere pesquisa que analisa a economia de compartilhamento em tempos de Covid-19 (Howson et al., 2020). Aliás, essa busca por um trabalho sem a mediação de um chefe, acaba por tornar a relação com o aplicativo atraente, pelo menos em um primeiro momento. Essa dimensão, entretanto, cria apenas uma falsa sensação de que o trabalho não é mediado por estreitas formas de controle, fazendo com que a precarização se instaure, pelo menos em um primeiro momento, de modo consentido.

E orbitando nessa discussão, entre os diferentes atores envolvidos, indubitavelmente, as organizações e, por consequência, as discussões sobre as relações de trabalho e as políticas e práticas de gestão de pessoas (em suas presenças ou ausências). Logo, as conexões entre relações de trabalho e gestão de pessoas são inevitáveis e não há como pensar políticas e práticas trabalhadas nas organizações sem considerar o impacto ocasionado para os modos de trabalhar e viver em uma perspectiva ampliada (Ferraz; Oltramari; Ponchirolli, 2011). 
Não se pode perder de vista também que, desde a década de 70, um "consenso neoliberal" ao redor do mundo passou gradualmente a liberar o Estado das suas obrigações de provisão pública (Harvey, 2016). Dentro de um falso discurso de austeridade que, ao limitar a atuação do Estado também precariza o sistema de seguridade social, bens comuns que antes eram ofertados de modo público, passam a ter a tendência de serem privatizados. Enquanto há o desmantelamento do Estado de bem-estar social, esse movimento, que serve aos interesses do mercado, intensificam a insegurança da classe que vive do trabalho, terminologia cunhada por Ricardo Antunes. A liberação das forças do capital leva "o capitalismo a revelar todos os desastres e injustiças que estão em seu âmago" (Sader, 2000:137). Para tanto, os impactos desta reestruturação produtiva em tempos de pandemia são decompostos pelas lentes de circunscritos fenômenos contemporâneos, a saber: da flexibilização dos vínculos e da jornada de trabalho (Alves, 2017) e da virtualização como parte constituinte da nova morfologia do trabalho (Antunes, 2011; 2008; Antunes; Braga, 2015).

A "plataformaização" do trabalho, neste sentido, vem para promover o que Harvey descreve como sendo o "ajuste” espaço-temporal, que é uma metáfora das soluções para as crises capitalistas. Ou seja, se trata de novos "arranjos institucionais capitalistas (regras contratuais e esquemas de propriedade privada) em formações sociais preexistentes” (2004:102 [tradução livre]) que, neste caso, traz modos distintos da velha forma de explorar os excedentes de trabalho.

Assim, no contexto contemporâneo, infere-se aqui que o esgotamento está: i) no modelo neoliberal que, ao depender de um crescimento exponencial ao infinito, já encontra-se com um limite em termos da exploração do trabalho humano e, ainda, dos recursos naturais usados de modo indiscriminado; ii) nos sujeitos que vivem do trabalho, especialmente em um contexto de precarização, como é o caso dos motoristas por aplicativo, que se veem em situação de exaustão dada às longas jornadas, à baixa remuneração e às condições insalubres; por fim, iii) a noção de esgotamento, dada a sobreposição destes fatores, consegue deslocar os sujeitos a um movimento de devir revolucionário, que possivelmente não poderia ser pensado em uma condição de 'possível', usando uma nomenclatura deleuziana.

\section{O esgotamento na reestruturação produtiva neoliberal}

No processo de reestabelecimento do ciclo do capital, há uma reorganização e reestruturação do processo produtivo, em que a classe trabalhadora é atingida material e subjetivamente. O plano material engloba as mencionadas formas de trabalho precário, parcial, 
terceirizado, subcontratado, no que se pode nominar subproletarização. Já o subjetivo, abarca a transição da acumulação rígida para a flexível, provocando transformações na essência e nas representações do trabalho (Antunes, 2006). A reorganização produtiva também é um período de transição na forma de acumulação. Com a crise mundial iniciada em 1973, o modelo fordista entra em colapso e cede lugar a um período de mudanças rápidas, pleno de incertezas e fluidez (Harvey, 2012).

\begin{abstract}
O neoliberalismo define certa norma de vida nas sociedades ocidentais e, para além dela, em todas as sociedades que as seguem no caminho da modernidade. Essa norma impõe a cada um de nós que vivamos num universo de competição generalizada, intima os assalariados e as populações a entrar em luta econômica uns contra os outros, ordena as relações sociais segundo o modelo do mercado, obriga a justificar desigualdades cada vez mais profundas, muda até o indivíduo, que é instado a conceber a si mesmo e a comportar-se como uma empresa. Há quase um terço de século, essa norma de vida rege as políticas públicas, comanda as relações econômicas mundiais, transforma a sociedade, remodela a subjetividade (Dardot; Laval, 2016:16).
\end{abstract}

Nas décadas de 1940 e 1950, em que perduraram as políticas keynesianas, o Estado proveu garantias de emprego, remuneração e condições mínimas de bem-estar, que funcionaram como amortecedores dos conflitos sociais distributivos. Foi possível, nesse período, conciliar transformações tecnológicas substanciais e modificações na atividade gerencial com a ampliação do emprego e a redução de desigualdades em boa parcela do mundo capitalista, principalmente a Europa, os Estados Unidos da América e o Japão. Ao mesmo tempo, encontrou-se espaço para a industrialização de economias consideradas atrasadas, como a América Latina e o Leste Asiático, com a forte e marcada presença do Estado na atividade econômica (Andrade, 1987). Este modelo tem sido defendido, em razão da atual pandemia, como o mais eficaz para recuperar emergencialmente as economias e dar condições de vida dignas à população, via ação estatal.

No novo modelo que se delineia, trabalhadores e trabalhadoras devem se adaptar às exigências impostas pela flexibilização do mercado, ajustando-se às suas atividades laborais e à plena disponibilidade que lhes é exigida para adequar-se às flutuações de demanda (Castel, 1999). Com a acumulação flexível surge um novo modelo de constrição do tempo no âmbito capitalista, surtindo no aumento da flexibilidade e da mobilidade das relações laborais. Os empregadores podem, a partir de então, controlar com maior pressão a força de trabalho, desorganizada e enfraquecida (Harvey, 2012).

Sendo a lógica do neoliberalismo sustentada, entre outros, pela necessidade do lucro exponencial, cuja demanda primeira é suprir o investimento da classe rentista, pode-se considerar que tal modelo econômico também se encontra em esgotamento. A saber, “é quase certo que a acumulação perpétua de capital a taxas exponenciais mediante a criação exponencial de dinheiro acabará em desastre, a não ser que venha acompanhada de outras adaptações" 
(Harvey, 2016:217). Salientando um possível esgotamento do próprio modelo neoliberal, Harvey (2016:225) destaca que

[...] o descontentamento, deve-se notar, não visa unicamente a capacidade técnica do capital de cumprir a promessa de um paraíso de emprego e consumo para todos, mas contesta cada vez mais as consequências degradantes para todos que tem de se submeter a regras e códigos sociais desumanos ditados pelo capital e por um Estado capitalista cada vez mais autocrático.

O novo padrão acumulativo compatibiliza componentes de continuidade e de descontinuidade quanto ao anterior. Com a incorporação de técnicas de gestão da força de trabalho e tecnologias relativas à era da informação, o novo modelo descentraliza a produção, tornando a estrutura mais flexível, e intensifica a exploração da força de trabalho, aumentando sua intensidade. Em igual passo, promove a desregulamentação dos direitos trabalhistas, aumenta a fragmentação no interior da classe trabalhadora, incentiva a terceirização e a desvalorização da mão de obra e desagrega a organização sindical combativa (Antunes, 2015; 2008; 2005).

O atual desenvolvimento econômico hegemônico, marcado pela concentração de renda e exclusão de direitos elementares, dá-se especialmente pela perda do direito básico ao trabalho formal (Sader, 2000). Essa tendência, que paulatinamente vinha fragilizando os vínculos trabalhistas, acaba por expor os trabalhadores ainda mais a precarização em tempos de pandemia. No Brasil, o número de trabalhadores sem carteira, entre 2016 e 2018, aumentou 9,3\%, o que representa o aumento de mais de 1 milhão de trabalhadores (Passos; Lupatini, 2020). Tal desresponsabilização do Estado, que serve de interesse às relações mercantis transnacionais, intensificam a insegurança da classe que vive do trabalho (Antunes, 2015; 2011; 2008). Assim, a liberação do capital sem a intermediação de políticas de regulamentação pode "revelar todos os desastres e injustiças que estão em seu âmago" (Sader, 2000:137), trazendo inúmeros prejuízos à saúde do trabalhador.

É possível identificar uma polarização no mercado de trabalho, havendo, "de um lado, grupos minoritários, com garantias contratuais, estabilidade, planos de carreira, bons salários, etc. De outro, massas crescentes de subempregados, de profissões desqualificadas, desprestigiadas e mal remuneradas" (CattanI, 1996: 30). O contexto heterogêneo do mercado pressupõe diversidade e descontinuidade do trabalho e do emprego, em formas que crescem ao ponto de superar as chamadas formas típicas. A precarização do trabalho e o próprio desemprego, assim, assumem um papel central no sistema capitalista contemporâneo, consequências da reestruturação produtiva (Castel, 1999). 
As formas de trabalho temporárias, informais ou terceirizadas passam a ser largamente adotadas pelo mercado, o qual exige, nas relações laborais, dinamismo, flexibilidade e polivalência. A terceirização do trabalho pode ser caracterizada como processo de administração a partir da qual a empresa ou instituição transfere suas atividades a terceiros, que no caso dos entregadores é a si mesmos, vistos como empreendedores, buscando enxugamento de quadros e aumento de competitividade.

Cabe salientar que a lógica da maximização dos ganhos é a de prevalecimento do capital sobre a força humana de trabalho, de sobrecarga dos trabalhadores e trabalhadoras, de adoecimentos físicos e psíquicos, de assédios e submissões pelo medo do desemprego, ou seja, de retorno ao século XIX e ao desvalor absoluto da vida operária, que aqui é sintetizado pelo conceito do esgotamento. Assim, o movimento de uberização é uma nova forma de organização, gerenciamento e controle, que apesar de vir ganhando visibilidade com o trabalho de plataforma, transcende-o e é fruto de décadas de eliminação de direitos, da dispersão global e, ao mesmo tempo, centralização das cadeias produtivas - aliadas à liberalização de fluxos financeiros e de investimento - e do desenvolvimento tecnológico (Figueiras; Antunes, 2020).

Uma rotina de trabalho intensa provoca a perda da noção de tempo e naturaliza o contato com os riscos e banaliza a exposição ao mal, ao precário. É no controle sobre o tempo de trabalho (Sennett, 2001) em que o sujeito passa a viver sobre a lógica do medo: que aliena, expõe a acidentes de trabalho, oprime e pode levar a crises de ansiedade e depressão. Ao contrário do que muitos supunham, esses regimes de trabalho marcados pela flexibilidade, atacam a rotina em nome da maior produtividade, dando outros contornos ao controle do trabalho, deixando-o mais sutil, mas não menos preocupante e culminando em um empobrecimento da vida.

E é quando percebemos isso, esse emaranhado de processos materiais e subjetivos, que o estado de esgotamento generalizado se torna um sintoma flagrante. Para Pelbart (2013), é necessário um certo grau de sufocamento para que os corpos possam vibrar em uma nova frequência; é necessária certa angústia que faz com que não se aguente mais tudo aquilo que afeta o corpo, a mente e a vida em suas múltiplas dimensões. Por fim, destaca-se que é em um jogo de forças ativas e reativas, que o esgotamento como categoria biopolítica nos leva a pensar que se há tentativa de controle e dominação, há tentativa de resistência. Além disso, importa dizer que entendemos aqui a necessidade de resistência como um ato coletivo, sobretudo, no maquinário capitalista neoliberal. 


\section{Considerações finais}

Circunscrevendo certo recorte temporal a essa análise, ao longo da pandemia da Covid19, tendo em vista a recomendação de que aglomerações e contatos físicos fossem evitados, muitos estabelecimentos comerciais foram fechados para atendimento ao público e o aumento de pedidos via aplicativos foram intensificados. Tanto as pessoas, como as organizações e os Estados se viram repentinamente impelidos a se adaptar a um novo e incerto cenário, que afeta as mais diversas relações sociais - dentre elas, as relações laborais. Destaca-se que o trabalho via aplicativos é um modo de organização que, viabilizado pelo momento tecnológico atual, tem encontrado no contexto brasileiro terreno fértil para sua expansão (IPEA, 2019) e que o "uberismo" vem a se aproveitar do trabalho atrelado à sobrevivência na captura da parcela cada vez mais crescente de desempregados na população e das pessoas que beiram o mercado formal de trabalho.

Não obstante, as crises econômicas e políticas ao longo da história vem acompanhadas de tensões das estruturas sociais, as quais acentuam as diferenças e os conflitos preexistentes, tanto étnicos quanto socioculturais, que atingem a sociedade e os indivíduos. O tempo atual, cuja marca de aceleração, especialmente na relação com o trabalho, parece ser ponto de consenso, coloca as plataformas digitais na condição no protagonismo. Se o trabalho humano segue sendo explorado conforme descrito por Marx, a novidade que surge com o advento da tecnologia são as formas perspicazes e sutis de atribuir um controle.

Neste sentido, há um cenário de falência do modelo neoliberal, que só ganhou algum fôlego com a entrada das plataformas digitais intermediando a exploração das corporações ao trabalhador. Ou seja, um modelo que depende do lucro exponencial e que pareceria estar chegando ao seu limite, conseguiu agora, mais uma vez, novo fôlego. Ao trabalhador, contudo, resta a sobrecarga exponencial que, no caso dos entregadores por aplicativo, chegou a um limite. Neste sentido, o esgotamento, que é físico, psíquico e emocional, foi traduzido em luta operária, como foi o caso da greve de julho de 2020. Curiosamente, as ferramentas digitais, que tanto servem para acelerar e controlar o trabalho, também foram usadas a serviço da mobilização.

Dessa forma, na atual crise sanitária da pandemia da Covid-19, os elementos do esgotamento são observados, enfatizando os danos às parcelas vulneráveis da população. Já em um cenário de estreitamento dos direitos sociais por parte do Estado e, concomitante a isso, na imersão de um modelo neoliberal centrado em um produtivismo desmedido, a atual pandemia, tende a aumentar as desigualdades sociais e econômicas na sociedade brasileira, penalizando ainda mais o trabalhador. Sem a garantia dos direitos sociais e com altos índices de desemprego, 
a intensificação da exploração do trabalho é facilitada. Entre a "escolha" de padecer de fome ou adoecer em jornadas exaustivas de trabalho, os limites da dignidade humana vão se estreitando, dando margem à barbárie.

A problemática em torno dos direitos e da precarização do trabalho, sobretudo, dos entregadores de aplicativos é um tema atual e pertinente para o futuro das organizações. Cabe considerar que, apesar da categoria trabalhar de forma completamente desprotegida em termos legais e não consolidar vínculo trabalhista, ainda assim, uma organização dos entregadores foi possível. Os mesmos meios digitais que serviram como ferramenta para impulsionar um massivo movimento de trabalho informal, também deram suporte às recentes organizações sindicais que estão acontecendo via redes sociais.

Há no trabalho digital o aprofundamento de características como a submissão livremente consentida e formas sutis de poder que produzem outros modos de controle da atividade laboral. Assim, é possível inferir que, apesar de a nova morfologia propiciar rupturas com os modelos burocráticos de gestão, o controle no e pelo trabalho não só não se extinguiu, como passou a assumir formas veladas de poder. Ou seja, o trabalho, apesar de ser mediado por um universo digital, segue sendo concreto, material, braçal e ainda mais alienante que um modelo fabril. Ainda, essa reformulação dos modos de sistematização organizacional que levam à exploração sutil do trabalhador sugere a necessidade de um direcionamento das pesquisas cuja abordagem elenque aspectos específicos de controle no trabalho em plataformas digitais.

Por fim, destaca-se que a pandemia da Covid-19 chega ao Brasil já encontrando um país assolado pelas desigualdades sociais, vivenciando a fase de financeirização da vida no modelo neoliberal, cujo pacote de práticas incluiu, ao longo das últimas décadas, a perda de direitos sociais. Nesse contexto, a situação dos trabalhadores desprotegidos, precarizados e informais tornou-se desoladora - ou seja, chegou à condição de esgotamento. Compreendendo esta crise sanitária como parte de um arranjo geopolítico de proporções globais que impacta significativamente as organizações, esse ensaio tratou dos entregadores como apenas uma das tantas categorias que poderiam ser abordadas para elucidar as condições precárias de trabalho em um contexto de enxugamento do Estado e de expansão neoliberal.

\section{Referências}

ABÍLIO, Ludmila. C. (2019), "Uberização: do empreendedorismo para o autogerenciamento subordinado". Psicoperspectivas, v. 18, n. 3, pp. 41-51.

ABÍLIO, Ludmila C. et al. (2020), "Condições de trabalho de entregadores via plataforma digital durante a Covid-19". Revista Jurídica Trabalho e Desenvolvimento Humano, Campinas, Edição especial dossiê covid-19, pp. 1-21. 
ABRASEL-ASSOCIAÇÃO BRASILEIRA DE BARES E RESTAURANTES (2020a), Do celular à mesa: como os apps de delivery transformam o mercado de bares e restaurantes (30 jan. 2020). Curitiba: Associação Brasileira de Bares e Restaurantes. [Consult. 03-07-2020]. Disponível em https://abrasel.com.br/noticias/noticias/do-celular-a-mesa-como-os-apps-de-delivery-transformam-omercado-de-bares-e-restaurantes/

ABRASEL-ASSOCIAÇÃO BRASILEIRA DE BARES E RESTAURANTES (2020b), Impactos da Covid-19 no Food service (29 jun. 2020). Curitiba: Associação Brasileira de Bares e Restaurantes. [Consult. 03-07-2020]. Disponível em https://pr.abrasel.com.br/noticias/noticias/impactos-da-covid19-no-food-service/

ALVES, Giovanni (2000), "Do 'novo sindicalismo' à 'concertação social': ascensão (e crise) do sindicalismo no Brasil (1978-1998)”. Revista de Sociologia e política, v. 15, pp. 111-124.

ALVES, Giovanni (2017), "The brazilian minotaur: labour reform and the historical development of capitalism in Brazil". Revista do Tribunal Regional do Trabalho da $15^{a}$ Região, Campinas, SP, v. 51, pp. 97-108. [Consult. 26-04-2021]. Disponível em: https://juslaboris.tst.jus.br/handle/20.500.12178/125460

ANDRADE, Rogério P. (1987), "Expectativas, incerteza e instabilidade no capitalismo: uma abordagem a partir de Keynes". Revista de Economia Política, v. 7, n. 2, pp. 81-95.

ANTUNES, Ricardo (2006), Adeus ao trabalho? ensaio sobre as metamorfoses e a centralidade do mundo do trabalho. São Paulo, Cortez.

ANTUNES, Ricardo (2005), Os sentidos do trabalho: ensaio sobre a afirmação e a negação do trabalho. São Paulo, Boitempo.

ANTUNES, Ricardo (2008), "Desenhando a nova morfologia do trabalho: As múltiplas formas de degradação do trabalho". Revista Crítica de Ciências Sociais, v. 83, pp. 19-34.

ANTUNES, Ricardo (2015), O caracol e sua concha: ensaios sobre a nova morfologia do trabalho. São Paulo, Boitempo.

ANTUNES, Ricardo (2011), "Os modos de ser da informalidade: rumo a uma nova era da precarização estrutural do trabalho?” Serviço Social \& Sociedade, São Paulo, n.107, pp.405-419, jul./set.

ANTUNES, Ricardo; BRAGA, Ruy (2015), Infoproletários: degradação real do trabalho virtual. São Paulo, Boitempo.

BARBOSA, Attila M. et al. (2011), "O empreendedor de si mesmo e a flexibilização no mundo do trabalho". Revista de Sociologia e Política, v. 19, n.38, pp. 121-140.

BBC NEWS BRASIL (2020), "Com pandemia, entregadores de app têm mais trabalho, menos renda e maior risco à saúde" (1 jul. 2020). BBC News Brasil. São Paulo: British Broadcasting Corporation no Brasil e na América Latina. [Consult. 03-07-2020]. Disponível em https://www.bbc.com/portuguese/brasil-53258465

BORGES, Samuel S. (2018), "Resenha de. 'A Nova Razão do Mundo: ensaio sobre a sociedade neoliberal' de Pierre Dardot e Christian Laval”. Plural, v. 25, n.1, pp. 178-185.

CARDOSO, Adalberto M. (2015), "Dimensões da crise do sindicalismo brasileiro". Caderno CRH, v. 28, n. 75: pp. 493-510.

CASTEL, Robert (1999), As metamorfoses da questão social: uma crônica do salário. Petrópolis, Vozes. 
CATTANI, Antônio D. (1996), Trabalho e autonomia. Petrópolis, Vozes.

COGGIOLA, Osvaldo.; KATZ, Cláudio (1996), Neoliberalismo ou crise do capital? São Paulo, Xamã.

CONSIGLIO, Marina (2020), "80\% dos restaurantes que trabalham com aplicativos estão insatisfeitos, diz pesquisa". Folha de São Paulo, Guia folha, 30 de junho de 2020 [Consult. 03-07-2020]. Disponível em https://folha.com/ac4en5po

DARDOT, Pierre; LAVAL, Christian (2016), A nova razão do mundo: ensaio sobre a sociedade neoliberal. São Paulo, Boitempo.

DE CARVALHO, Felipe. S. E.; DOS SANTOS PEREIRA, Súllivan.; SOBRINHO, Gabriela. S. (2020), "\#BrequeDosApps e a organização coletiva dos entregadores por aplicativo no Brasil". Revista Jurídica Trabalho e Desenvolvimento Humano, 3 [Consult. 26-04-2021]. Disponível em https://doi.org/10.33239/rjtdh.v3.85

DE VIVAR, Rodrigo D. et al. (2017), “A potência de viver: Deleuze e a arte”. Psicologia \& Sociedade, v. 29 , pp. 1-8.

DELEUZE, Gilles (2010), Sobre o teatro: um manifesto de menos/O esgotado. Rio de Janeiro, Editora Zahar.

DELEUZE, Gilles (1990), Pourparlers. Paris, Les Éditions de Minuit.

EL PAÍS (2020), "Entregadores de aplicativos fazem primeira grande paralisação da categoria no Brasil”. El país, São Paulo. [Consult. 04-07-2020]. Disponível em: https://brasil.elpais.com/brasil/2020-0702/entregadores-de-aplicativos-fazem-primeira-grande-paralisacao-da-categoria-no-brasil.html

FERRAZ, Alexandre S. (2018), "Quando os trabalhadores param? Reinterpretando a ocorrência de greves no Brasil”. Lua Nova: Revista de Cultura e Política, v. 104, pp. 167-200.

FERRAZ, Deise. L. S.; OLTRAMARI, Andrea. P.; PONCHIROLLI, Osmar (2015), Gestão de pessoas e relações trabalho. São Paulo, Boitempo.

FIGUEIRAS, Vitor; ANTUNES, Ricardo (2020), "Plataformas digitais, uberização do trabalho e regulação no capitalismo contemporâneo". Contracampo, v. 39, n. 1, pp. 12-26 [Consult. 10-03-2021]. Disponível em https://periodicos.uff.br/contracampo/article/view/38901

FOUCAULT, Michel (2005), Vigiar e punir: nascimento da prisão. 30. ed. Petrópolis, Vozes.

GEPOLT- GRUPO DE PESQUISA GESTÃO DE POLÍTICAS DE TRABALHO (2020), "Trabalho informal e políticas públicas no contexto da Covid-19: problemática latinoamericana, soluções locais". In: MACAMBIRA, Junior (org). Desmonte do estado e das políticas públicas: retrocesso do desenvolvimento e aumento das desigualdades no Brasil. Fortaleza: Instituto de Desenvolvimento do Trabalho.

HABERMAS, Jürgen (1987), "A nova intransparência: a crise do estado de bem-estar social e o esgotamento das energias utópicas". Novos estudos CEBRAP, v. 18, pp. 103-114.

HAN, Byung-Chul (2017), Sociedade do cansaço. $2^{\mathrm{a}}$ ed. ampliada. Petrópolis, RJ, Vozes.

HARVEY, David (2004), "El "nuevo" imperialismo: acumulación por desposesión." Socialist Register, v. 40, n. 1, pp. 95-126.

HARVEY, David (2012), Condição pós-moderna. São Paulo, Loyola. 
HARVEY, David (2016), 17 contradições e o fim do capitalismo. São Paulo, Boitempo Editorial.

HARVEY, David (2020), "Política anticapitalista en tiempos de coronavírus". in AGAMBEN, Giorgio (org). Sopa de Wuhan: pensamiento contemporâneo en tiempos de pandemias. E-book, ASPO.

HOWSON, Kelle, et al. (2020), “Just because you don't see your boss, doesn't mean you don't have a boss: Covid-19 and Gig Worker Strikes across Latin America". International Union Rights, v. 27, n. 3, pp. 20-28.

IPEA-INSITUTO DE PESQUISA ECONÕMICA APLICADA (2019), "Mercado de Trabalho - IPEA". Carta de Conjuntura, 45 ( $4^{\circ}$ trim.).

IBGE (2021), Instituto Brasileiro de Geografia e Estatística. [Consult. 04-04-2021]. Disponível em https://www.ibge.gov.br/explica/desemprego.php

MACHADO, Leandro (2020), "Greve dos entregadores: o que querem os profissionais que fazem paralisação inédita" (1 jul. 2020). BBC News Brasil. São Paulo: British Broadcasting Corporation no Brasil e na América Latina. [Consult. 03-07-2020]. Disponível em https://www.bbc.com/portuguese/brasil-53124543

MARX, Karl (1989), O capital: crítica da economia política. Trad. Reginaldo Sant'Anna. 13. ed. Rio de Janeiro: Bertrand Brasil, Livro 1, v. 1 e 2.

MORETTO, Amilton; MACAMBIRA, Júnior (2020), "Intensificação do trabalho por conta própria: novas questões para a velha desproteção social". in MACAMBIRA, Junior (org). Desmonte do estado $e$ das políticas públicas: retrocesso do desenvolvimento e aumento das desigualdades no Brasil. Fortaleza: Instituto de Desenvolvimento do Trabalho.

NARDI, Henrique C; TITTONI, Jaqueline; BERNARDES, Jefferson S. (2000), "Subjetividade e Trabalho". in CATTANI, A. D (org.). Trabalho e Tecnologia: dicionário crítico. Petrópolis, Vozes, pp. 240-246.

PASSOS, Saionara.; LUPATINI, Márcio (2020), “A contrarreforma trabalhista e a precarização das relações de trabalho no Brasil”. Revista Katálysis, v. 23, n. 1, pp. 132-142.

PELBART, Peter P. (2013), O avesso do niilismo: cartografias do esgotamento. São Paulo, N-1 edições.

PRESTHUS, Robert (1962), The Organizational Society. New York, Knopf.

PUELLO-SOCARRÁS, José. F. (2014), “El Capitalismo del Buen Salvaje. Nuevo neoliberalismo e inclusión social." Periferias. Revista de Ciencias Sociales. Buenos Aires, Fundación de Investigaciones Sociales y Políticas, v. 23, n. 22, pp. 99-115.

SADER, Emir (2000), Século XX: uma biografia não autorizada: o século do imperialismo. São Paulo, FPA.

SAFATLE, Vladimir (2016), O circuito dos afetos: corpos políticos, desamparo e o fim do indivíduo. Autêntica.

SENNETT, Richard (2001), A corrosão do caráter. Rio de Janeiro, Record. 


\begin{abstract}
Starting from the understanding that the precariousness process deepens and intensifies with the so-called uberization, this theoretical essay discusses the working conditions of delivery app workers, category that marked its demands face of the amplified vulnerabilities in the the Covid-19 pandemic context. Reflecting on these movements, the exhaustion notion is raised as the central point of a sociopsychological analysis of work that correlates the macrosocial neoliberal economy dimension with the productive restructuring harmful effects. Thus, it is inferred that the notion of exhaustion has the potential to displace subjects to a revolutionary becoming movement, which presumably would not be thought of as a 'possible' condition, using the Deleuzian nomenclature.
\end{abstract}

Keywords: precarious work; delivery app workers; exhaustion; Covid-19.

\title{
Resumen
}

Partiendo de la comprensión de que el proceso de precariedad se profundiza y se intensifica con la llamada uberización, este ensayo teórico discute las condiciones de trabajo de los repartidores de aplicaciones, categoría que marcó sus reclamos ante las vulnerabilidades amplificadas en el contexto de la pandemia de Covid-19. Reflexionando sobre estos movimientos, se plantea la noción de agotamiento como punto central de un análisis sociopsicológico del trabajo que correlaciona la dimensión macrosocial de la economía neoliberal con los efectos nocivos de la reestructuración productiva. Así, se infiere que la noción de agotamiento tiene el potencial de desplazar a los sujetos hacia un devenir revolucionario, lo que presumiblemente no sería concebido como una condición 'posible', utilizando la nomenclatura deleuziana.

Palabras clave: precarización del trabajo; repartidores de aplicaciones; agotamiento; Covid-19. 